Article

\title{
Traffic Accident Spatial Simulation Modeling for Planning of Road Emergency Services
}

\author{
Amin Naboureh ${ }^{1,2}{ }^{\oplus}$, Bakhtiar Feizizadeh ${ }^{3}$, Abbas Naboureh ${ }^{4}$, Jinhu Bian ${ }^{1}{ }^{(0)}$, \\ Thomas Blaschke $\left.^{5}{ }^{(}\right)$, Omid Ghorbanzadeh ${ }^{5, *}$ (D) and Meisam Moharrami ${ }^{3}$ \\ 1 Research Center for Digital Mountain and Remote Sensing Application, Institute of Mountain Hazards and \\ Environment, Chinese Academy of Sciences, 610041 Chengdu, China \\ 2 University of Chinese Academy of Sciences, 100049 Beijing, China \\ 3 Department of Remote Sensing and GIS, University of Tabriz, 51666 Tabriz, Iran \\ 4 Department of Nursing, Behbahan faculty of medical sciences, Ahvaz Jundishapur University of Medical \\ Sciences, 6361796819 Ahvaz, Iran \\ 5 Department of Geoinformatics - Z_GIS, University of Salzburg, 5020 Salzburg, Austria \\ * Correspondence: omid.ghorbanzadeh@stud.sbg.ac.at
}

Received: 22 July 2019; Accepted: 16 August 2019; Published: 25 August 2019

\begin{abstract}
The appropriate locations of road emergency stations (RESs) can help to decrease the impact of traffic accidents that cause around 50 million injuries per year worldwide. In this research, the appropriateness of existing RESs in the Khuzestan province, Iran, was assessed using an integrated fuzzy analytical hierarchy process (FAHP) and geographic information system (GIS) approach. The data used in this research were collected from different sources, including the department of roads, the department of health, the statistics organization, forensics, police centers, the surveying and geological department, remotely-sensed and global positioning system (GPS) data of accident high crash zones. On the basis of previous studies and the requirements of the Ministry of Health and Medical Education, as well as the department of roads of Iran for the location of RESs, nine criteria and 19 sub-criteria were adopted, including population, safety, environmental indicators, compatible area in RES, incompatible area in RES, type of road, accident high crash zones, traffic level and performance radius. The FAHP yielded the criteria weights and the ideal locations for establishing RESs using GIS analysis and aggregation functions. The resulting map matched the known road accident and high crash zones very well. The results indicated that the current RES stations are not distributed appropriately along the major roads of the Khuzestan province, and a re-arrangement is suggested. The finding of the present study can help decision-makers and authorities to achieve sustainable road safety in the case study area.
\end{abstract}

Keywords: road emergency stations (RESs); traffic police; geographic information system (GIS); fuzzy analytical hierarchy process (FAHP); road safety

\section{Introduction}

Traffic accidents cause around 50 million injuries per year worldwide and are a significant concern for public health [1-3]. On the basis of findings by the World Health Organization (WHO), about 1.35 million people died worldwide because of road traffic accidents in 2016. Road traffic injuries are considered as one of the main reason for death the younger generation (5-29 years old) [4]. Although low-income and middle-income countries have only $50 \%$ of the world's vehicles, $90 \%$ of the world's fatalities on the roads occur in these countries [4]. Pre-hospital care has a significant role in handling and decreasing the traffic accident effects and saving the lives of people, and emergency medical services (EMS) play an indisputable role in this task [5,6]. EMS is a system that provides a variety 
of medical services, such as pre-hospital medical and transportation, trauma care and assistance for people who in need of emergency care [7]. Definitions differ, but in most cases, the geographical availability and provision of services are introduced as main factors [8,9]. Choosing optimal locations for emergency stations can help to achieve these aims. The locations of road emergency stations (RESs) are one of the most critical factors that can play a role in the degree of damage caused by accidents. Proper distribution of RESs is key to being able to respond to accidents within a standard time [10]. Therefore, determining optimum locations for RESs is a vital issue that road administrators face [11].

After cardiovascular diseases, road accidents are the main reason for death in Iran [12-14]. Iran has a very high rate of road accidents; it is twenty times greater than that of the world's average [15]. The number of fatalities per 100,000 people per year for Iran is 32.1 (Figure 1). According to a UNICEF report, every 19 min one person passes away on Iran's roads, and every 2 min somebody is informed that one of his/her family members has survived a crash accident but with severe injury that may cause lifetime disability [16]. Each year, road traffic accidents cause the death of almost 28,000 people and disable or injure 300,000 more in Iran [12]. Cost of traffic fatalities in Iran is estimated at $\$ 6$ billion U.S. every year, which covers $5 \%$ of the gross national product the country $[15,16]$, with this also applying to the Khuzestan province. This province, which is the focus of the current research, is the leader in terms of road accidents in Iran. Nearly 1300 people lose their life, and more than 15,000 people get injured or disabled in road traffic accidents in the Khuzestan province each year $[12,17]$.

Although site selection science has witnessed a great improvement in the last two decades, there are still several challenges in this topic. Many of these location selection methods are based on a fundamental analysis of experiences, or even predilection. In the scientific literature, several sophisticated approaches have been proposed that utilize statistical and mathematical tools. However, these methods are criticized for their inability and lack of user-friendliness in processing data and presenting the results [18]. To tackle this, geographic information system (GIS) can be used to manage and analyze spatial data, and GIS literature provides a variety of tools for location-based services and optimization of site selection [11]. It has been proven that GIS is a robust tool to depict and visualize location characteristics and determine various location-based services [19,20]. Moreover, spatial data should be analyzed and specified using an efficient spatial context [21]; it is broadly known that GIS, with its spatial analysis option, has an effective ability to identify healthcare site selection [22]. To optimum site selection for RESs, the criteria requirements are almost clear, in general, as mentioned above, and employing indicators such as traffic, road, distance, high crash zones, etc., can significantly increase the certainty of results [23].

Moreover, applying an integrated approach in GIS for location-based service analysis, such as the fuzzy analytical hierarchy process (FAHP), will provide a suitable methodology for RESs [24,25]. FAHP has a hierarchical structure. It is based on pairwise comparisons of individual opinions, reducing inconsistency and model uncertainty in decisions [24-27]. RESs must be located carefully because, in an emergency, staff should be able to reach the site of the accident within $5 \mathrm{~min}$ [28]. Hence, considering this crucial temporal aspect, the coverage matrix is essential for describing alternative locations [23].

By reviewing various studies, the significant role of pre-hospital services and emergency in a road accident has improved $[17,29,30]$. Early research has shown that good quality pre-hospital services have a high impact on the reduction of the death rate caused by brain trauma resulting from accidents [24,25]. Nowadays, GIS spatial analysis and decision-making systems enable the identification of high crash zones of roads, helping in developing crisis management programs for providing adequate and fast pre-hospital services in the event of an accident and preventing an avoidable leading cause of death [31-33]. Hence, providing timely services and ultimately covering a part of the road safety strategy in Iran, as well as analyzing the geographical distribution of the existing emergency stations and recommending appropriate places for establishing new stations, can be helpful. Considering this statement, the main objective of the present study was to analyze the locations of RESs in the Khuzestan province using GIS-based decision analysis. 


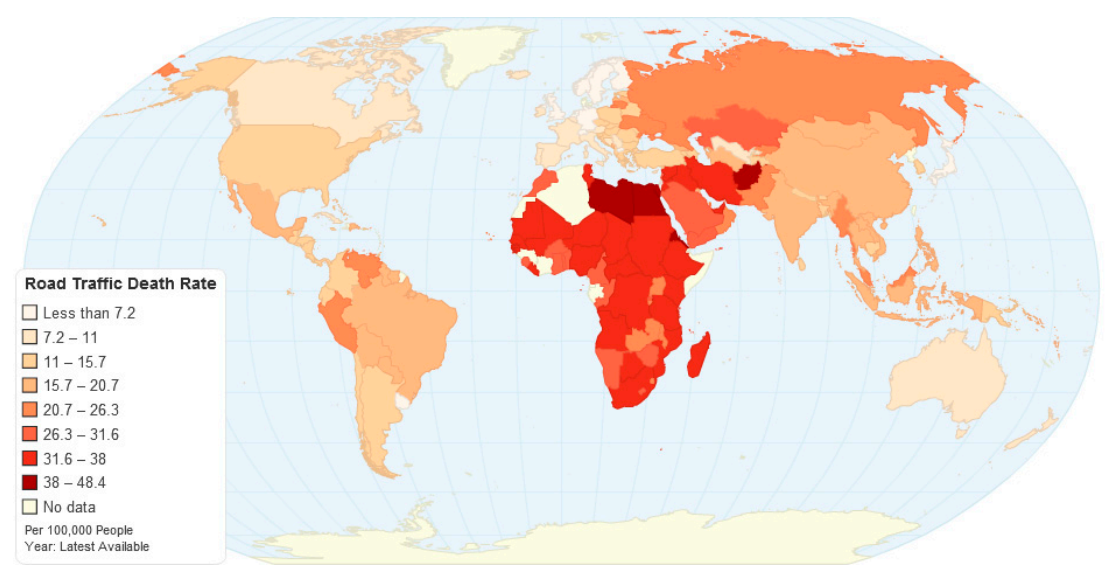

Figure 1. World statistics of road traffic deaths, and rank of Iran in this list.

\section{Materials and Methods}

\subsection{Case Study Area}

Khuzestan Province, with an area of 63,633 square kilometers, is located in southwestern Iran (Figure 2). This area is important in terms of the economy of the country, and for housing and industrial activities. According to the 2011 census, it consists of 24 counties, 61 cities and is home to 4,421,643 people. The sum total of the land routes of the province is $4727 \mathrm{~km}$, of which $2153 \mathrm{~km}$ are main roads, and $2573 \mathrm{~km}$ are secondary roads. The high number of recorded road accidents in this province is due to its topography, heavy traffic resulting from oil and gas industries and the fact that it is a center of trade and transportation in the southern part of Iran, as well as having access to pilgrimage sites and five roads connecting with neighboring countries.
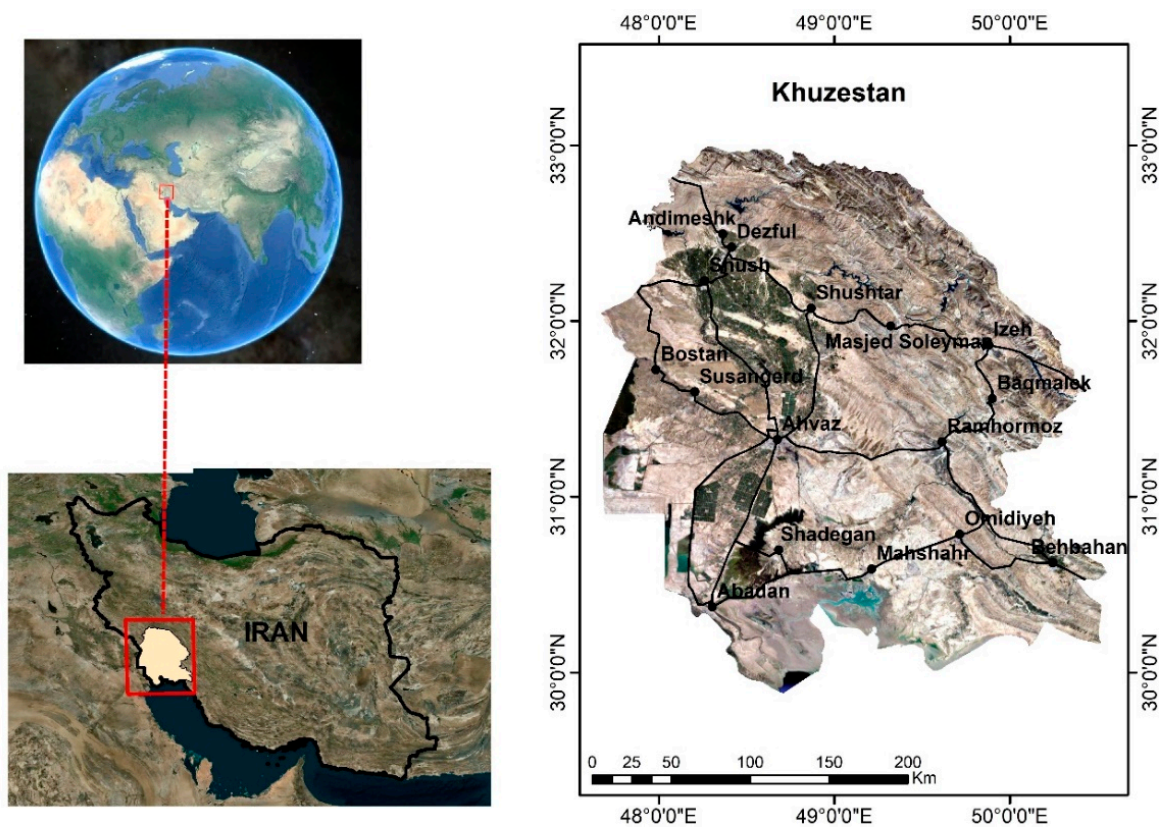

Figure 2. Location map of the area under study, Khuzestan Province.

\subsection{Dataset}

The present research is both descriptive and analytical in terms of its nature and methodology, and how it is applied in terms of the overall goal. Its results can be adapted in the programs and policies of managers in road emergency departments. An extensive literature review was employed, 
along with interviews and questionnaires, to determine and extract the criteria needed for the research. The data used in this research were collected from different sources; traffic and road type data from the department of roads, the population information from the statistics organization, accident fatal data from forensics, performance radius of RESs and accident injuries data from the department of health and road accident data from police centers. Data for the incompatible area, compatible area and safety criteria were obtained from the surveying and geological department. Moreover, the topographic data were derived from a topographic 1:25,000 map and the shuttle radar topography mission (SRTM) digital elevation model (DEM) data with a spatial resolution of $30 \mathrm{~m}$. We employed field observation data collected by global positioning system (GPS) to identify high crash zones and for validation purposes. After a preparation step, all datasets were imported into the GIS software and converted into raster format to form the basis of the considered criteria.

\subsection{Methodology}

The first step in the methodology was to recognize the criteria affecting the location of RESs. To this end, on the basis of previous studies [27,34-38], several factors affecting the location of RESs were identified and submitted to 30 experts for initial ranking. The selected experts who represented the local and national university, the state RESs and EMS staff and operators filled the pairwise matrices of our study. They were asked to evaluate the importance of each criterion critically. Finally, nine casual criteria with one sub-criteria were specified to achieve the ultimate goal of the research. Then, the weights of each criterion, together with its sub-criteria, were computed using FAHP. In doing so, the final map of proposed sites for RESs was prepared by applying GIS-based aggregation functions. Figure 3 presents the main steps performed for the methodology.

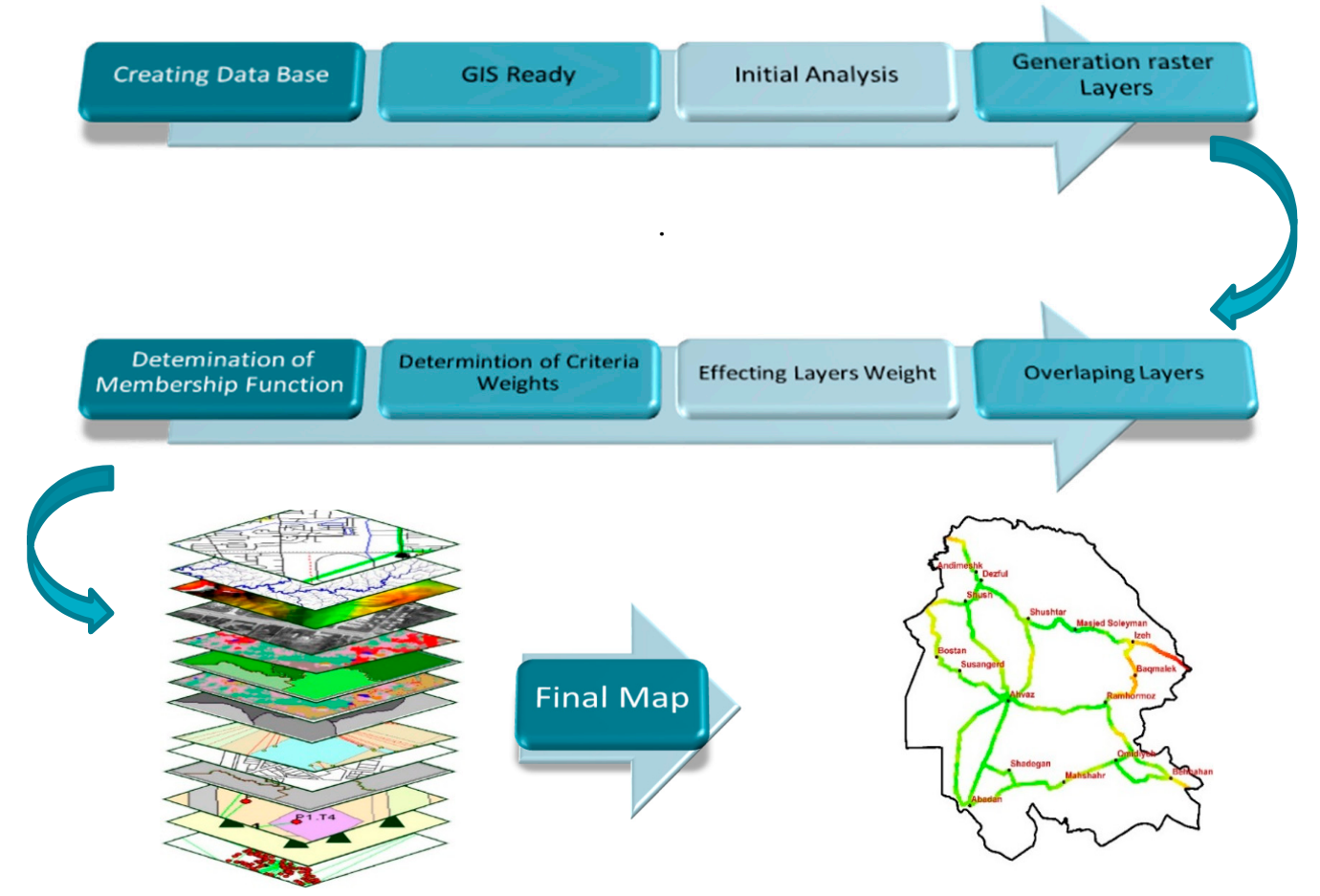

Figure 3. The main scheme of the presented research. GIS = geographic information system.

\subsubsection{Fuzzy Set Theory (FST) for Criteria Weighting}

The fuzzy set theory (FST) mimics human judgment in that it deals with the uncertainty associated with measurement indicators [39]. In the Boolean logic, every element is considered as either true or false. However, in fuzzy logic, elements can be considered as both true and false within different degrees. Thus, each element can be in a set by a specific degree. The FST is practical when it is difficult 
to extract precise decisions by human judgment. Decision-makers and policymakers also desire natural language expressions instead of crisp numbers [40]. The FST has been a significant step towards representing vague and incomplete data because of its ability to deliver a methodology for computing directly with words. The FST makes it possible to use three key factors, namely FST, membership function and fuzzy numbers, to change vague data into practical data efficiently. Fuzzy numbers are natural generalizations of ordinary values. The triangular and trapezoidal fuzzy numbers are usually used to capture the vagueness of the parameters related to selecting the alternatives [26]. In the present study, we used triangular and trapezoidal fuzzy numbers to prioritize the suitability of land for RESs. These numbers are expressed with boundaries instead of crisp numbers to reflect the fuzziness, as decision-makers select the alternatives in the pairwise comparison matrices.

A fuzzy number M on R is referred to a triangular fuzzy number (TFN) (Figure 4) in the case that its membership function is given by [41]

$$
\begin{aligned}
\mu_{a}(x) & =R \rightarrow[0,1] \\
\mu_{\ddot{a}}(x) & = \begin{cases}\frac{x}{m-1}-\frac{1}{m-1} & x \in[l, m] \\
\frac{x}{m-u}-\frac{u}{m-u} & x \in[m, u] . \\
0 & \text { otherwise }\end{cases}
\end{aligned}
$$

Moreover, we state a fuzzy number M on R to be a trapezoidal fuzzy number in the case that its membership function is

$$
\begin{gathered}
\mu_{\ddot{a}}(x)=R \rightarrow[0,1] \\
\mu_{\ddot{a}}(x)=\left\{\begin{array}{cc}
\frac{x}{n-1}-\frac{1}{n-1} & x \in[l, n] \\
1 & x \in[n, m] \\
\frac{x}{m-u}-\frac{u}{m-u} & x \in[m, u] \\
0 & \text { otherwise }
\end{array},\right.
\end{gathered}
$$

by considering two TFNs- $\mathrm{M}_{1}$ and $\mathrm{M}_{2}$-with $\mathrm{M}_{1}=\left(\mathrm{l}_{1}, \mathrm{~m}_{1}, \mathrm{u}_{1}\right)$ and $\mathrm{M}_{2}=\left(\mathrm{l}_{2}, \mathrm{~m}_{2}, \mathrm{u}_{2}\right)$. Their operation laws are as follows:

$$
\begin{gathered}
\left(\mathrm{l}_{1}, \mathrm{~m}_{1}, \mathrm{u}_{1}\right)+\left(\mathrm{l}_{2}, \mathrm{~m}_{2}, \mathrm{u}_{2}\right)=\left(\mathrm{l}_{1}+\mathrm{l}_{2}, \mathrm{~m}_{1}+\mathrm{m}_{2}, \mathrm{u}_{1}+\mathrm{u}_{2}\right), \\
\left(\mathrm{l}_{1}, \mathrm{~m}_{1}, \mathrm{u}_{1}\right) \times\left(\mathrm{l}_{2}, \mathrm{~m}_{2}, \mathrm{u}_{2}\right)=\left(\mathrm{l}_{1} \times \mathrm{l}_{2}, \mathrm{~m}_{1} \times \mathrm{m}_{2}, \mathrm{u}_{1} \times \mathrm{u}_{2}\right), \\
\left(l_{1}, m_{1}, \mathrm{u}_{1}\right)^{-1}=\left(\frac{1}{l_{1}}, \frac{1}{m_{1}}, \frac{1}{u_{1}}\right) .
\end{gathered}
$$

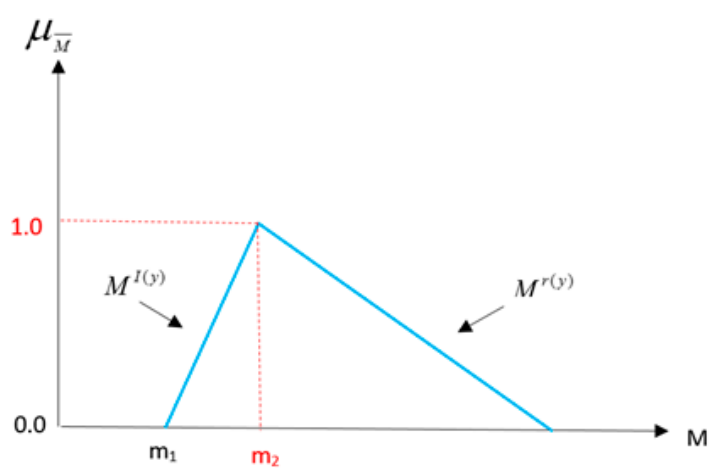

Figure 4. The fuzzy triangular set.

\subsubsection{Integration Approach of Fuzzy AHP (Analytical Hierarchy Process)}

The AHP method was proposed by Thomas L. Saaty (1980) [42]. This method is a widely used multiple criteria decision-making approach in GIS spatial analysis [43]. Although the AHP method aims to capture experts' knowledge, the conventional AHP still cannot take into account the human 
thinking style. The traditional AHP method has some limitations by using the exact values to express the decision-makers' judgments in a comparison of alternatives [25,44]. As the comparison of indicators in the traditional AHP method is based on expert judgments, some degree of inconsistency may transfer from uncertain comparisons to the results [39-43,45].

Moreover, experts are usually from different fields and may not be entirely sure about the importance of some of the indicators and their comparisons [25]. The inconsistency may be exacerbated when experts and decision-makers compare a wide range of factors related to different matters. Comparisons of decision-makers are the primary source to weigh the factors based on their importance regarding the specific problem. These comparisons are represented qualitatively by different linguistic variables. The relation among the quantitative values and linguistic variables are represented in Table 1.

Table 1. Triangular fuzzy number of linguistic variables.

\begin{tabular}{ccc}
\hline Linguistic Variables & Triangular Fuzzy Numbers & Reciprocal Triangular Fuzzy Numbers \\
\hline Extremely strong & $(9,9,9)$ & $(1 / 9,1 / 9,1 / 9)$ \\
Very strong & $(6,7,8)$ & $(1 / 8,1 / 7,1 / 6)$ \\
Strong & $(4,5,6)$ & $(1 / 6,1 / 5,1 / 4)$ \\
Moderately strong & $(2,3,4)$ & $(1 / 4,1 / 3,1 / 2)$ \\
Equally strong & $(1,1,1)$ & $(1,1,1)$ \\
Intermediates & $(7,8,9),(5,6,7)$, & $(1 / 9,1 / 8,1 / 7),(1 / 7,1 / 6,1 / 5)$, \\
& $(3,4,5),(1,2,3)$ & $(1 / 5,1 / 4,1 / 3),(1 / 3,1 / 2,1)$ \\
\hline
\end{tabular}

The AHP method is often criticized because of its use of an unbalanced scale of comparisons and its limitation to adequately handle the associated uncertainty in the pairwise comparison process [45]. To overcome these shortcomings, the fuzzy analytical hierarchy process was developed for solving hierarchical problems. Most decision-makers frequently find that it is more reliable to give interval judgments than fixed value comparisons. This is because they are often unable to express explicit preferences [46]. Thus, fuzzy AHP is applied to solve hierarchical fuzzy problems. The integration of the AHP with the fuzzy set theory is helpful to reduce the subjectivity in the factor weightings. Therefore, fuzzy numbers were specified to make comparative pairwise and structuring of the resultant matrices. Let $\widetilde{A}$ be the pairwise comparison matrix that is prepared with the fuzzy numbers [41,47], then

$$
\widetilde{A}=\left[\begin{array}{cccc}
(1,1,1) & \left(l_{12}, m_{12}, u_{12}\right) & \ldots & \left(l_{1 n}, m_{1 n}, u_{1 n}\right) \\
\left(l_{21}, m_{21}, u_{21}\right) & (1,1,1) & \ldots & \left(l_{2 n}, m_{2 n}, u_{2 n}\right) \\
\vdots & \vdots & \ddots & \vdots \\
\left(l_{n 1}, m_{n 1}, u_{n 1}\right) & \left(l_{n 2}, m_{n 2}, u_{n 2}\right) & \ldots & (1,1,1)
\end{array}\right]
$$

where each component of this matrix follows the condition that if $\widetilde{a}=\left(l_{i j}, m_{i j}, u_{i j}\right)$ then $\widetilde{a}_{i j}^{-1}=$ $\left(\frac{1}{l_{i j}}, 1 / m_{i j}, 1 / u_{i j}\right)$ for $1, j, \ldots, n$ and $i \neq j$.

Let $\mathrm{M}_{\mathrm{i}}=\left(\mathrm{l}_{\mathrm{ij}}, \mathrm{m}_{\mathrm{ij}}, \mathrm{u}_{\mathrm{ij}}\right)$ be a TFN. The phases of the extent analysis approach can be summarized as follows:

$$
\begin{gathered}
S_{i}=\sum_{j=1}^{m} M_{i j} \times\left[\sum_{i=1}^{n} \sum_{j=1}^{m} M_{i j}\right]^{-1}, \\
\text { s.t }=\sum_{j=1}^{m} M_{i j}=\left[\sum_{j=1}^{n} l_{i j}, \sum_{j=1}^{m} m_{i j}, \sum_{j=1}^{m} u_{i j},\right] \text { for } i=1,2, \ldots, n, \\
\sum_{i=1}^{n} \sum_{j=1}^{m} M_{i j}=\left(\sum_{i=1}^{n} \sum_{j=1}^{m} l_{i j}, \sum_{i=1}^{n} \sum_{j=1}^{m} m_{i j}, \sum_{i=1}^{n} \sum_{j=1}^{m} u_{i j}\right), \\
{\left[\sum_{i=1}^{n} \sum_{j=1}^{m} M_{i j}\right]^{-1}=\left(\frac{1}{\sum_{i=1}^{n} \sum_{j=1}^{m} l_{i j}}, \frac{1}{\sum_{i=1}^{n} \sum_{j=1}^{m} m_{i j}}, \frac{1}{\sum_{i=1}^{n} \sum_{j=1}^{m} u_{i j}}\right),}
\end{gathered}
$$


where in this case $\mathrm{d}$ is the ordinate of the highest intersection point between $\mu \mathrm{M} 1$ and $\mu \mathrm{M} 2$. To perform this computation, the values of $V\left(S_{j} \geq S_{i}\right)$ and $V\left(S_{i} \geq S_{j}\right)$ with $S_{i}$ and $S_{j}$ have to be compared.

As $S_{j}=\left(l_{j}, m_{j}, u_{j}\right)$ and $S_{i}=\left(l_{i}, m_{i}, u_{i}\right)$ are considered as two triangular fuzzy numbers (Figure 5 ), the possibility degree of $S_{j}=\left(l_{j}, m_{j}, u_{j}\right) \geq S_{i}=\left(l_{i}, m_{i}, u_{i}\right)$ is defined as

$$
v\left(S_{j} \geq S_{i}\right)=\operatorname{heigh}\left(S_{i} \cap S_{j}\right)=u_{s_{j}}(d)= \begin{cases}1 & \text { if } m_{j} \geq m_{i} \\ 0 & \text { if } l_{i} \geq u_{j} \\ \frac{l_{i}-u_{j}}{\left(m_{j}-u_{j}\right)-\left(m_{i}-l_{i}\right)} & \text { otherwise }\end{cases}
$$

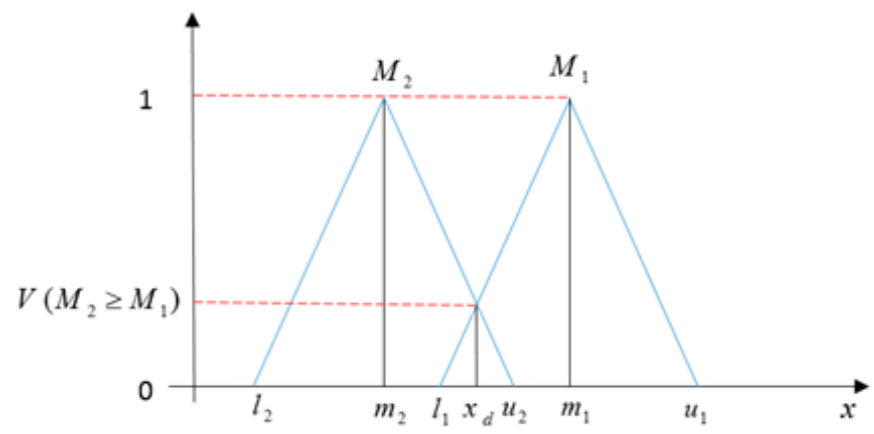

Figure 5. The degree of possibility $V\left(M_{2} \geq M_{1}\right)$.

For the possible degree of a convex fuzzy number to be larger than $k$, convex fuzzy $M_{i}(i=1,2$, $\ldots, k)$ numbers can be defined by

$$
\mathrm{V}\left(\mathrm{S} \geq \mathrm{S}_{1}, \mathrm{~S}_{2}, \ldots, \mathrm{S}_{\mathrm{k}}\right)=\mathrm{V}\left[\left(\mathrm{S} \geq \mathrm{S}_{1}\right) \text { and }\left(\mathrm{S} \geq \mathrm{S}_{2}\right) \text { and } \ldots \text { and }\left(\mathrm{S} \geq \mathrm{S}_{\mathrm{k}}\right)\right]=\operatorname{Min} \mathrm{V}\left(\mathrm{S} \geq \mathrm{S}_{\mathrm{i}}\right), \mathrm{i}=1,2,3, \ldots, \mathrm{k} \text {. }
$$

Now we can have $d\left(A_{i}\right)=\min V\left(S_{i} \geq S_{k}\right)$ for $k=1,2, \ldots, n$. At that point, the weight vector is given by

$$
W^{\prime}=\left(d^{\prime}\left(A_{1}\right), d^{\prime}\left(A_{2}\right), \ldots, d^{\prime}\left(A_{n}\right)\right)^{T} .
$$

Via normalization, the normalized weight vectors are

$$
W=\left(d\left(A_{1}\right), d\left(A_{2}\right), \ldots, d\left(A_{n}\right)\right)^{T}
$$

where $\mathrm{W}$ is a non-fuzzy number.

\subsubsection{Standardization of the Criteria Based on TFNs:}

In most cases, after the criteria and the sub-criteria are determined they require standardization, since the criteria cannot be compared. Data standardization is a process in which the criteria are converted and re-scaled to be comparable. The common method for the standardization of the criteria is based on the FST. In the fuzzy operation, the inputs are captured and, using the corresponding membership functions such as a linear function, an appropriate grade is attributed to each [47]. However, there are other factors that increase the ability of the FST to be applied for the standardization of the criteria, such as uncertainty in decision-making and imprecise data [48]. Following the preparation of the desired layers, it was necessary to convert the criteria into raster format to apply the membership functions and standardize them. To this end, using the Euclidean distance function for continuous data as well as discrete data, each criterion was given a score in the range of zero to one based on the opinions of the experts. They were then converted into a raster layer. 


\subsection{Implementation of the Workflow}

Determining the effective factors is considered one of the most important and fundamental steps in determining the locations of RESs. Therefore, the nine criteria and the 19 sub-criteria used in the present research were adopted based on previous studies and the requirements of the Ministry of Health and Medical Education, as well as the department of roads of Iran for the location of RESs. These nine criteria are explained in the following list:

1. Population: The density of the population close to the road is a major factor affecting the location of RESs. Expansion of residential area may increase the road accident risk [13].

2. Safety: The safety of the RESs is related to their proximity to the road outposts and their distance from faults or watercourses. This is because certain phenomena, such as faults, may cause instability, and proximity to police stations can be effective in creating order and security when necessary.

3. Natural Factors: Natural factors, such as slope elevation and topography of the region, influence the location and ability to establish RESs. Moreover, road slope can have an effect on the road traffic level where drivers should be careful about their speed because of the high level of slope [49].

4. The Incompatible Area in RESs: This term refers to the forms of land use that damages RESs when they are in close proximity with one-another, harming the mental health of people. They include gas stations and residential use, and the privacy of transmission lines of electricity, gas and phone.

5. The Compatible Area in RESs: This term refers to forms of land use that deliver favorable results in the RESs. Proximity to Red Crescent centers and traffic police lead to synergies in accomplishing traffic missions where the presence of relief agencies beside one-another facilitates providing services and rescuing the injured. Furthermore, barren lands provide open space for relief helicopters to land, in addition to facilitating RES construction.

6. Road Type: The road type is of prime importance in this kind of location analysis because roads with two-way crossings incur more accidents than expressways. It was reported that the number of road accidents on two-way crossings is higher than expressways [50].

7. Traffic Level: This is one of the important factors affecting the location of RESs. An increase in traffic leads to a growth in the number of accidents.

8. High Crash Zones: According to the conducted studies, accidents are more likely to occur in certain parts of the roads, and these are known as high crash zones or road accident blackspots. The proximity of the RESs to blackspots is a crucial factor.

In the present research, the number of intensity-methods of accidents was employed to evaluate the high crash zones. In this method, an index, known as coefficient $\mathrm{P}$, was determined for every position. This index is obtained from the following equation (from the Iran Road Maintenance Organization):

$$
\mathrm{P}>30
$$

The $\mathrm{P}$ index is obtained using the following formula:

$$
P=9 X+5 Y+0.5 Z
$$

According to this equation: $P$ represents the high crash zones, $X$ shows the number of fatal accidents, $\mathrm{Y}$ indicates the number of accidents causing injury and $\mathrm{Z}$ is the number of accidents causing only damage to property.

9. Distance (or performance radius of existing RESs): According to the existing regulations (the organization regulation for the comprehensive coverage of pre-hospital emergency medical services), RESs should be established every $20 \mathrm{~km}$ or every $40 \mathrm{~km}$ at most [51-53]. In addition, the distance 
from existing stations should not be less than $15 \mathrm{~km}$. The distance from the villages to the nearest RES should not exceed $40 \mathrm{~km}[53,54]$. The Ministry of Health and Medical Education is required to provide emergency medical services to the villagers and nomads across the country through emergency stations in rural health centers that are more than $40 \mathrm{~km}$ from the pre-hospital emergency centers and are not located on the main roads of the country.

\section{Results}

From 2011 until 2017, on the basis of the data obtained from the Legal Medicine Organization and the emergency centers of the Khuzestan province, the number of the reported road accidents in this province was 6303, causing 877 deaths and 1210 injuries (Table 2). The roads from Ahwaz to Andimeshk and Ahwaz to Ramhormoz had the highest death rate among all the roads, with 141 and 137, respectively. The lowest death rate of 14 was recorded on the road from Susangerd to Andimeshk. In this period, the number of EMS call-outs was 9755 . The highest number of call-outs occurred in March, which coincides with the Iranian New Year holidays. The highest number of call-outs was at the Andimeshk and Ahwaz road emergency stations, with a total of 1539. The FAHP found that high crash zones were the primary factor among the nine casual criteria with a value of 0.279 . Table 3 shows the weight of each criterion affecting the location of RESs in the Khuzestan province. The calculations and analysis of the achieved statistics identified only 40 high crash zones from among 400 sections (Table 2).

Table 2. Number of accidents on roads in the Khuzestan province (2011-2017).

\begin{tabular}{cccccc}
\hline Road Names & $\begin{array}{c}\text { Accidents } \\
\text { (Fatal) }\end{array}$ & $\begin{array}{c}\text { Accidents } \\
\text { (Injury) }\end{array}$ & $\begin{array}{c}\text { Accidents } \\
\text { (Damage) }\end{array}$ & $\begin{array}{c}\text { High Crash } \\
\text { Zones }\end{array}$ \\
\hline $\mathbf{1}$ & Ahvaz to Shushtar & 70 & 90 & 210 & 4 \\
$\mathbf{2}$ & Ahvaz to Andimeshk & 141 & 177 & 677 & 6 \\
$\mathbf{3}$ & Ahvaz to Susangerd & 29 & 49 & 187 & 2 \\
$\mathbf{4}$ & Ahvaz to Khoramshahr & 98 & 131 & 314 & 3 \\
$\mathbf{5}$ & Ahvaz to Ramhormoz & 137 & 170 & 531 & 5 \\
$\mathbf{6}$ & Ahvaz to Abadan & 102 & 167 & 487 & 4 \\
$\mathbf{7}$ & Ahvaz to Omidiyeh & 77 & 102 & 521 & 3 \\
$\mathbf{8}$ & Omidiyeh to Behbehan & 14 & 27 & 99 & 2 \\
$\mathbf{9}$ & Omidiyeh to Abadan & 47 & 75 & 312 & 2 \\
$\mathbf{1 0}$ & Ramhormoz to Izeh & 83 & 113 & 467 & 4 \\
$\mathbf{1 1}$ & Izeh to Andimeshk & 64 & 83 & 314 & 3 \\
$\mathbf{1 2}$ & Susangerd to Andimeshk & 15 & 26 & 97 & 2 \\
\hline
\end{tabular}

Table 3. Evaluation criteria of road emergency stations (RES) and fuzzy analytical hierarchy process (AHP) weights.

\begin{tabular}{llc}
\hline \multicolumn{1}{c}{ Main Criteria } & \multicolumn{1}{c}{ Sub-Criteria } & Weights \\
\hline & From city $(0.250)$ & 0.034 \\
Performance radius (0.137) & From rural (0.250) & 0.034 \\
& From existing RES (0.500) & 0.069 \\
Safety (0.081) & River (0.105) & 0.008 \\
& Fault (0.258) & 0.020 \\
Natural causes (0.042) & Police station (0.637) & 0.053 \\
& Slope (0.460) & 0.019 \\
Incompatible area in RES (0.060) & Topography (0.540) & 0.023 \\
& Residential area (0.637) & 0.038 \\
Compatible area in RES (0.060) & Agriculture land (0.258) & 0.007 \\
& Bare land (0.249) & 0.015 \\
Type of road (0.176) & Parking (0.157) & 0.014 \\
Traffic (0.141) & Station of Red Crescent Society (0.594) & 0.011 \\
Population (0.024) & Two-way crossing road (0.333) & 0.035 \\
High crash zones (0.279) & Highway (0.667) & 0.059 \\
Sum (1.000) & Traffic (0.141) & 0.117 \\
\hline
\end{tabular}


After determining the weights, fuzzy maps (Figure 6) were prepared for each of the criteria and sub-criteria, and the following results were obtained.

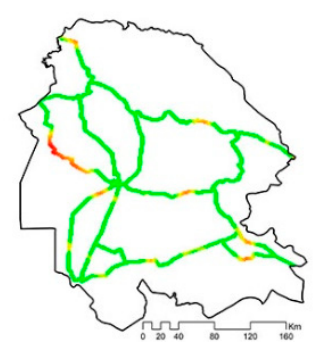

Agriculture Land

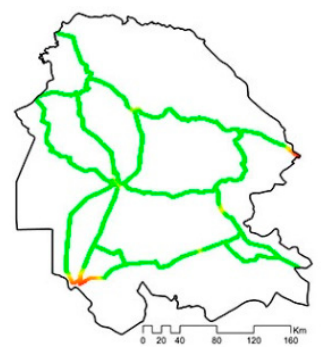

Gas Station

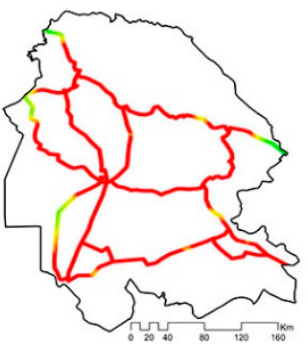

Highway

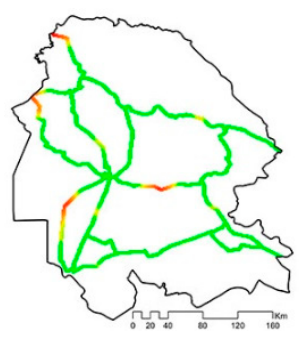

Residential Area

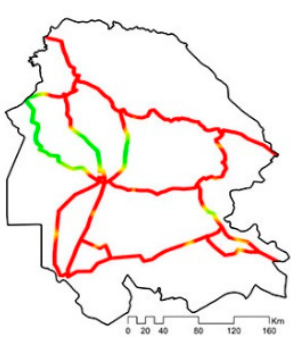

Traffic

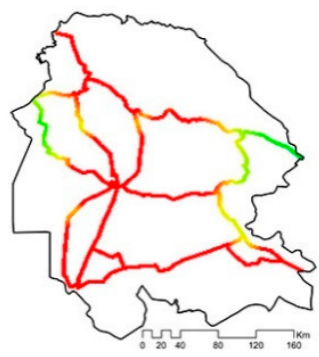

Bare Land

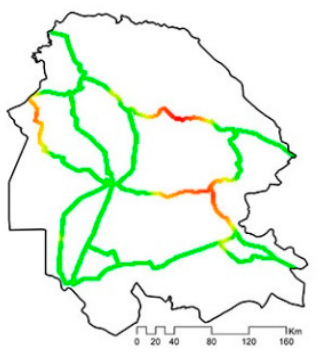

Red Crescent Society Stations

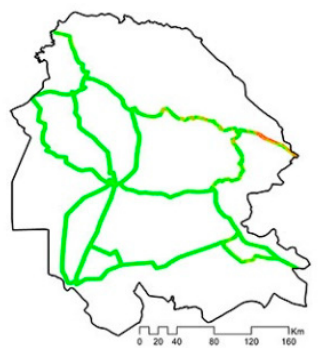

Slope

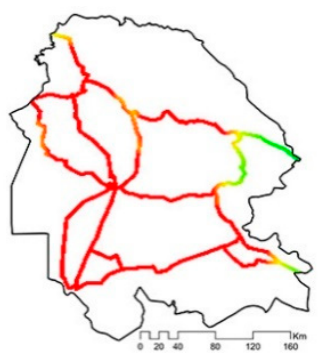

High Crash Zone

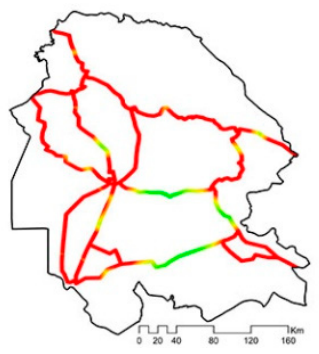

Two-Way Crossing Road

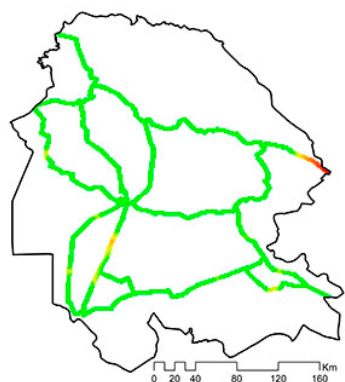

Performance Radius from City

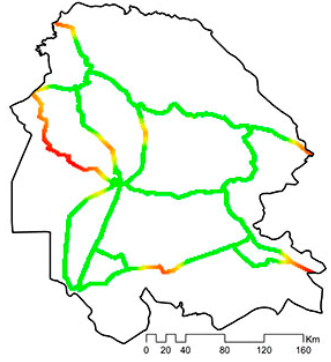

Performance Radius from RESs

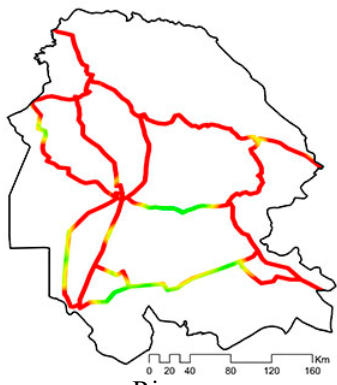

River

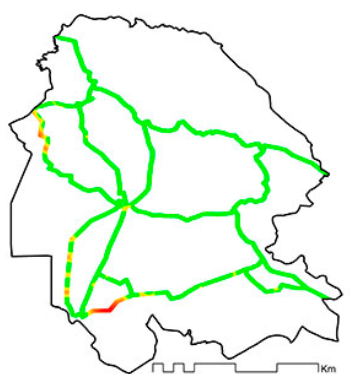

Performance Radius from Village

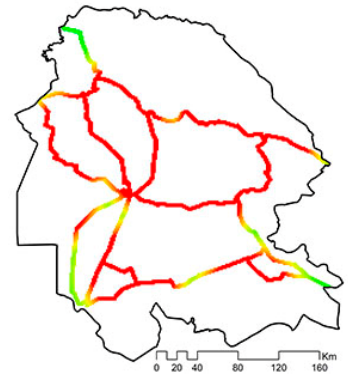

Parking

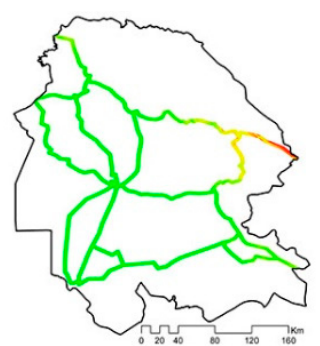

Elevation

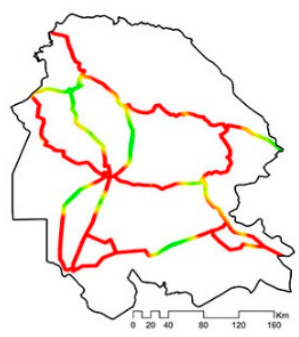

Fault

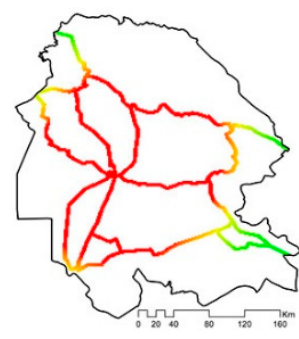

Population

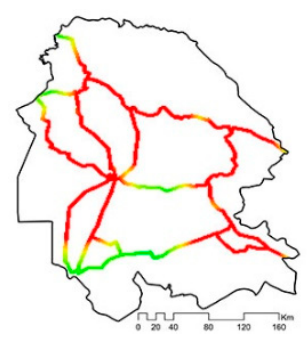

Police Stations

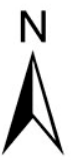

Risk

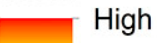

Low

Legend

Figure 6. Fuzzy maps for criteria and sub-criteria. 
Finally, one the basis of the filled pairwise comparison matrices by the experts who were mentioned in the methodology section, all prepared fuzzy maps of the conditioning factors were overlaid with the respective FAHP weights in Arc GIS software. Thus, the final map was generated using the fuzzy maps for each factor and the corresponding weight for proposed points for establishing RESs (Figure 7).

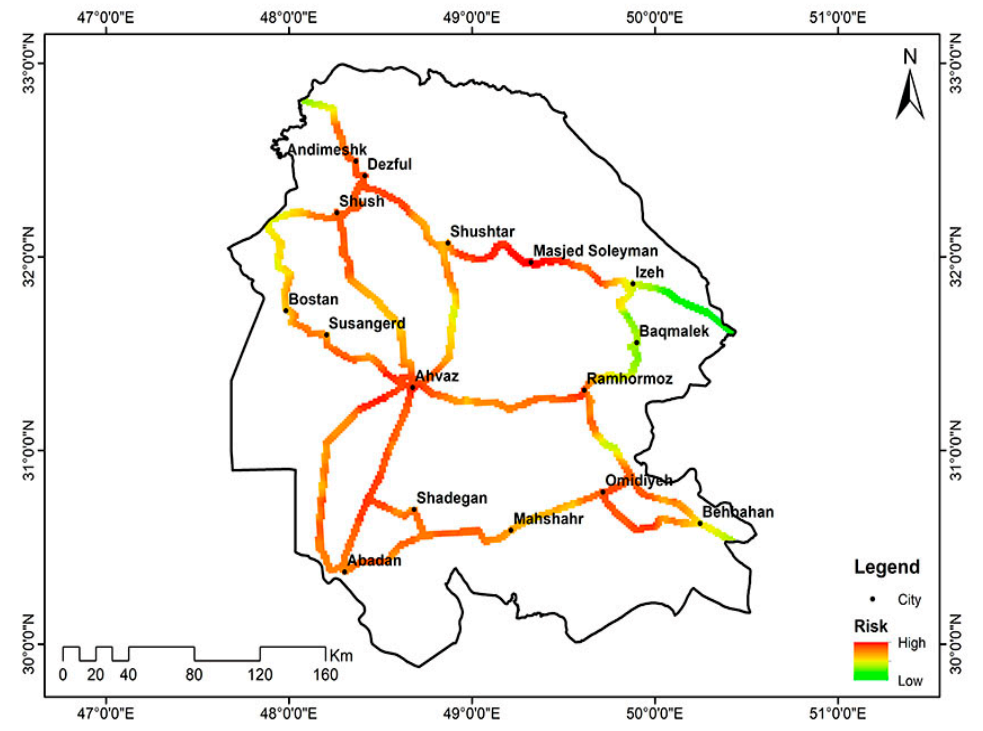

Figure 7. The resulting map of proposed points for establishing RES.

\section{Discussion}

According to the accident statistics provided by the traffic police of the Khuzestan province during the 2011-2017 period, it was noted that 40 high crash zones exist in the connecting axes of the province's road network. In total, most of the accidents occurred in the axes of Ahwaz-Andimeshk, Ahwaz-Izeh and Abadan-Mahshahr during the 6 years. The highest number of fatal accidents occurred on the main roads leading to Ahwaz, Andimeshk and Abadan. At an increasing distance from Ahvaz city, which is the capital of the province, the density of fatal accidents decreases. This requires the serious attention of authorities to these critical areas. The obtained information yielded that the number of deaths in the categories of drivers/passengers of busses and drivers/passengers of heavy trucks in the Khuzestan province is higher than the average of the country. In contrast, in the categories of drivers/passengers of four-wheeled cars and pedestrians have lower shares (Figure 8).

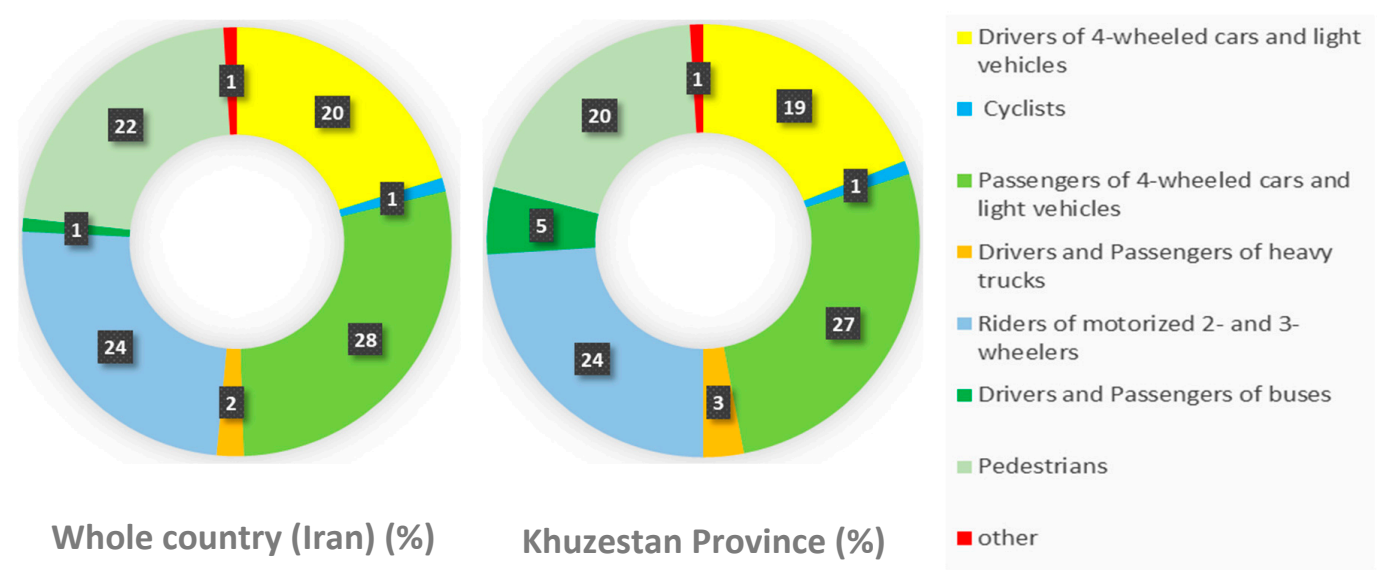

Figure 8. Comparison between the Khuzestan province and the whole of Iran in the rate of deaths by road user category. 
As illustrated in Figure 9, the number of reported road accidents witnessed a moderate increase; it reached to 1098 from 794. The number of accident injuries almost had the same trend; it increased from 150 to 187. In contrast, the number of accident deaths slightly reduced (from 135 to 125).

口Accidents (Fatal) $\quad$ accidents (Injuries) $\quad$ Reported Accidents Number

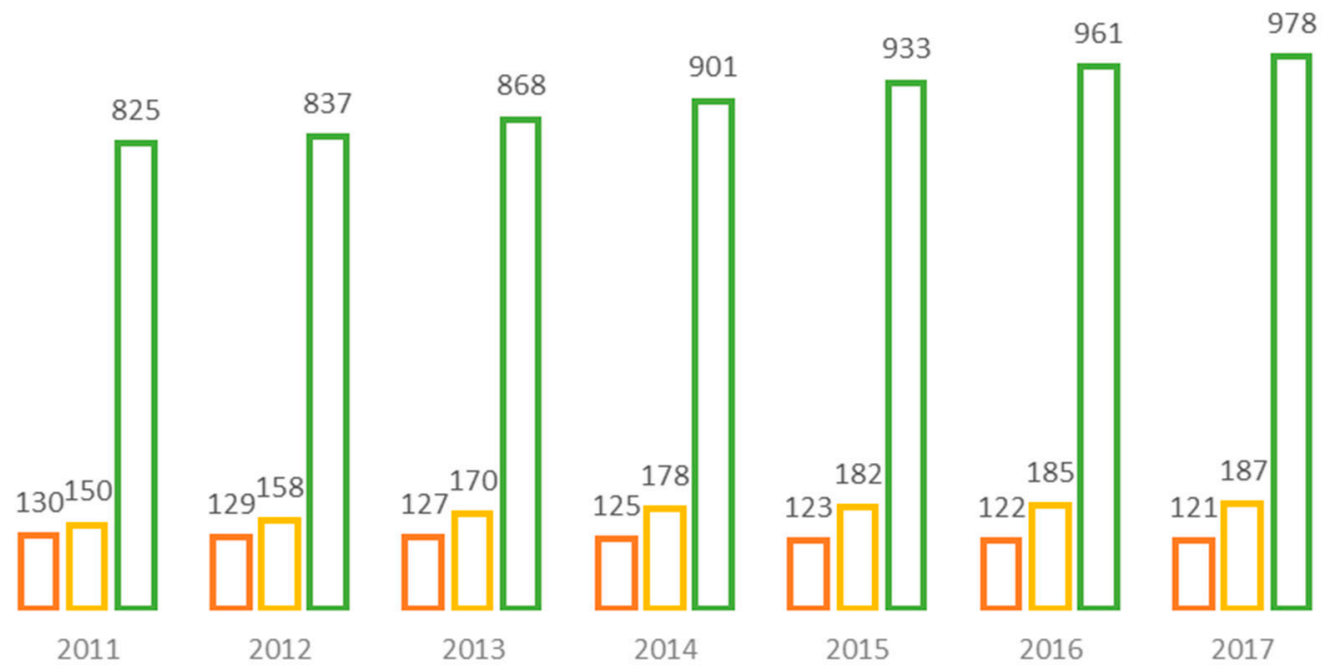

Figure 9. The number of reported accidents, injuries and fatal on the Khuzestan province's roads per year between 2011 and 2017, based on the data obtained from the Legal Medicine Organization and the emergency centers of the Khuzestan province.

Three elements, namely the driver, the road and the vehicle, have the most significant impact on the occurrence of road accidents in this region, based on the data obtained from the police center of the Khuzestan province. Because of their errors and interaction with other causes, for example, vehicles or roadway design, drivers are often the cause of crashes [55].

Furthermore, an inappropriate road network can increase the crash risk, as it determines how road users perceive their environment, meaning that the roadway offers instructions to the drivers on what they should be doing. Negative road engineering features include those where a road defect directly triggers a crash, or where some factor of the road environment misleads a driver and thereby creates human errors [56,57]. The results obtained in several recent studies [58-60] illustrate that human behaviors are the cause of accidents in almost $70 \%$ of cases (due to a lack of adherence to the laws and regulations, disregarding warning signs, a low level of education and a lack of familiarity with the minimum technical requirements of cars). In $15 \%$ of the cases, the cause of the accident is attributable to the structure of the road (for example, the shape of the bends, road surface slope and mountain passes). In a further $15 \%$ of cases, the cause is related to the vehicles (due to depreciation and malfunctioning). On the basis of objective evidence and the accident reports from the traffic police and the emergency department, the statistics indicate the cause of accidents in the Khuzestan province can be attributed to the driver, the road and the vehicle in $75 \%, 15 \%$ and $10 \%$ of cases, respectively.

After comparing the final map with the other existing maps of the practical factors, it was revealed that the ultimate map matched well with the maps of road traffic and high crash zones. It seems that areas with a high density of fatal accidents have a lack of RESs and, therefore, a distinct need for the establishment of new RESs (Figure 10). This matter confirms the excellent performance of the FAHP method and the GIS in the identification of locations for the establishment of RESs. The results are consistent with those from Goli et al., 2015, and Ohta et al., 2007 [36,61]. 


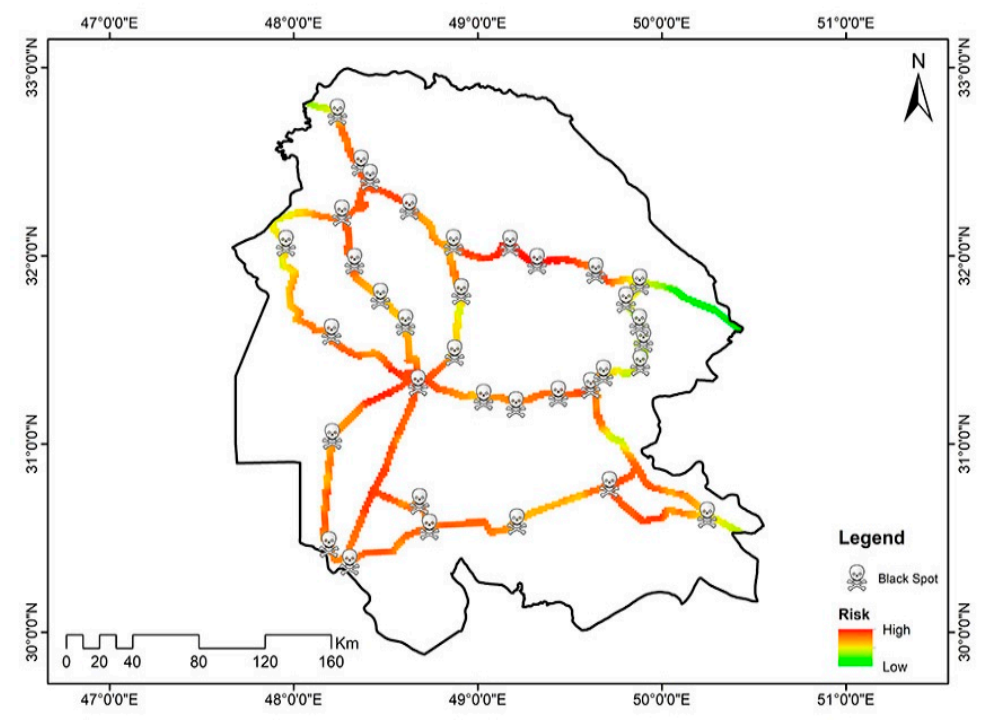

Figure 10. Matching of the final map with the map of high crash zones (black spot).

\section{Conclusions}

In this study, the appropriateness of existing RESs in the Khuzestan province, Iran, was assessed using an integrated FAHP and GIS. One of the core purposes of adopting GIS in different applications is to make a support system for spatial decision-making because, in most cases, spatial issues are semi-structured. Optimum site selection is considered as one of these spatial problems. On the basis of the last reports of the Iranian road safety commission, as well as successful experiences from other countries, the following are some suggestions to decrease the number of road traffic deaths and injuries in the Khuzestan province:

- According to the respondents, the highest impact on reducing the number of fatal injuries on the connecting roads of the province can be achieved by proper quality equipment of rescue posts and qualified medical staff, and it is thus proposed that these posts be equipped by the Ministry of Health and Medical Education immediately.

- The healthcare organization of the Khuzestan province should give priority to the standardization of the equipment and facilities of RESs.

- Improving the situation of media, which has an incredible impact on society, is considered as a powerful tool to provide people with awareness about road accident troubles.

- Using new technologies to record and analyze big data, as well as upgrading the existing roads to record violations, would effectively reduce the number of road violations by the drivers and, thus, lead to fewer road accidents.

- Conducting stricter laws on vehicle safety standard certificates, as the current situation of vehicles in Iran — of which most are made in Iran—is not acceptable, and they still require improvement in the safety topic.

- Improving the situation of roads in the Khuzestan province, as more than $80 \%$ of roads in this province are two-way crossing roads, with the province having heavy traffic.

The number of accidents causing death and injuries in the Khuzestan province is high enough to demand attention from decision-makers and authorities. Moreover, the appropriate locations of RESs not only can help to decrease the humanitarian aspects of road accident death and injuries, but also can reduce road crash costs on the economy. To conclude, the current RES stations are not distributed appropriately along the major roads of the Khuzestan province, and a re-arrangement is suggested.

Author Contributions: Conceptualization, A.N. (Amin Naboureh); methodology, A.N. (Amin Naboureh), B.F.; software, A.N. (Amin Naboureh), M.M.; validation, A.N. (Abbas Naboureh); formal analysis, O.G. and 
T.B.; investigation, A.N. (Amin Naboureh); resources, A.N. (Abbas Naboureh); data curation, A.N. (Abbas Naboureh); writing-original draft preparation, A.N. (Amin Naboureh); writing-review and editing, O.G. and T.B.; supervision, J.B.; project administration, A.N. (Abbas Naboureh); funding acquisition, J.B.

Funding: Open Access Funding by the Austrian Science Fund (FWF) through the GIScience Doctoral College (DK W 1237-N23).

Conflicts of Interest: The authors declare no conflict of interest.

\section{References}

1. Khorasani-Zavareh, D.; Khankeh, H.; Mohammadi, R.; Laflamme, L.; Bikmoradi, A.; Haglund, B. Post-crash Management of road traffic injury victims in Iran. Stakeholders' views on current barriers and potential facilitators. Inj. Prev. 2012, 18, A209-A210. [CrossRef]

2. McIlroy, R.; Plant, K.; Hoque, M.; Jianping, W.; Kokwaro, G.; Vũ, N.; Stanton, N. Who is responsible for global road safety? A cross-cultural comparison of Actor Maps. Accid. Anal. Prev. 2019, 122, 8-18. [CrossRef]

3. Peden, M.; Scurfield, R.; Sleet, D.; Mohan, D.; Hyder, A.A.; Jarawan, E.; Mathers, C.D. World Report on Road Traffic Injury Prevention; World Health Organization: Geneva, Switzerland, 2004.

4. World Health Organization. Global Status Report on Road Safety 2015; World Health Organization: Geneva, Switzerland, 2015.

5. Bahadori, M.; Nasiripur, A.; Tofighi, S.; Gohari, M. Emergency medical services in Iran: An overview. Australas. Med. J. (Online) 2010, 3, 335. [CrossRef]

6. Kepaptsoglou, K.; Karlaftis, M.G.; Mintsis, G. Model for planning emergency response services in road safety. J. Urban Plan. Dev. 2011, 138, 18-25. [CrossRef]

7. Li, Y.; Zheng, Y.; Ji, S.; Wang, W.; Gong, Z. Location selection for ambulance stations: A data-driven approach. In Proceedings of the 23rd SIGSPATIAL International Conference on Advances in Geographic Information Systems, Seattle, WA, USA, 3-6 November 2015; ACM: New York, NY, USA, 2015; p. 85.

8. Andersen, R.M. Revisiting the behavioral model and access to medical care: Does it matter? J. Health Soc. Behav. 1995, 36, 1-10. [CrossRef]

9. Khan, A.A. An integrated approach to measuring potential spatial access to health care services. Socio-Econ. Plan. Sci. 1992, 26, 275-287. [CrossRef]

10. Phillips, R.L., Jr.; Kinman, E.L.; Schnitzer, P.G.; Lindbloom, E.J.; Ewigman, B. Using geographic information systems to understand health care access. Arch. Fam. Med. 2000, 9, 971. [CrossRef]

11. Chehreghan, A.; Rajabi, M.; Pazoki, S.H. Developing a Novel Method for Optimum Site Selection Based on Fuzzy Genetic System and GIS. Int. J. 2013, 3, 165-174.

12. Bhalla, K.; Naghavi, M.; Shahraz, S.; Bartels, D.; Murray, C.J. Building national estimates of the burden of road traffic injuries in developing countries from all available data sources: Iran. Inj. Prev. 2009, 15, 150-156. [CrossRef]

13. Ganji, S.; Rassafi, A. Measuring the road traffic safety performance of Iranian provinces: A double-frontier DEA model and evidential reasoning approach. Int. J. Inj. Control Saf. Promot. 2018, 26, 156-169. [CrossRef]

14. Paravar, M.; Hosseinpour, M.; Salehi, S.; Mohammadzadeh, M.; Shojaee, A.; Akbari, H.; Mirzadeh, A.S. Pre-hospital trauma care in road traffic accidents in kashan, iran. Arch. Trauma Res. 2013, 1, 166. [CrossRef]

15. UNICEF. Road Traffic Injuries in Iran and Their Prevention, a Worrying Picture; UNICEF: Tehran, Iran, 2012.

16. UNICEF. Road Traffic Injuries in Iran and Their Prevention, a Worrying Picture; UNICEF: Tehran, Iran, 2014.

17. Behbahani, N.R.; Mohammadi, M.J.; Nazari, S.S.H.; Ghadirzadeh, M.; Hassanipour, S. Studying the epidemiology of fatal traffic accidents in the Khuzestan Province. Jundishapur J. Health Sci. 2016, 8, e32114. [CrossRef]

18. Cheng, E.W.; Li, H.; Yu, L. A GIS approach to shopping mall location selection. Build. Environ. 2007, 42, 884-892. [CrossRef]

19. Pirnazar, M.; Karimi, A.Z.; Feizizadeh, B.; Ostad-Ali-Askari, K.; Eslamian, S.; Hasheminasab, H.; Ghorbanzadeh, O.; Hamedani, M.H. Assessing flood hazard using GIS based multi-criteria decision making approach; study area: East-Azerbaijan province (Kaleybar Chay Basin). J. Flood Eng. 2017, 8, $203-223$.

20. Moslem, S.; Ghorbanzadeh, O.; Blaschke, T.; Duleba, S. Analysing Stakeholder Consensus for a Sustainable Transport Development Decision by the Fuzzy AHP and Interval AHP. Sustainability 2019, 11, 3271. [CrossRef] 
21. Ghorbanzadeh, O.; Feizizadeh, B.; Blaschke, T. Multi-criteria risk evaluation by integrating an analytical network process approach into GIS-based sensitivity and uncertainty analyses. Geomat. Nat. Hazards Risk 2018, 9, 127-151. [CrossRef]

22. Saeidian, M.; Aminzadeh, J. Location emergency stations in urban emergency rescue services using GIS and network rescue services optimization. Tagh 2010, 49, 1-4.

23. Aslani, M.; Alesheikh, A.A. Site selection for small gas stations using GIS. Sci. Res. Essays 2011, 6, 3161-3171.

24. Büyüközkan, G.; Çifçi, G.; Güleryüz, S. Strategic analysis of healthcare service quality using fuzzy AHP methodology. Expert Syst. Appl. 2011, 38, 9407-9424. [CrossRef]

25. Vahidnia, M.H.; Alesheikh, A.A.; Alimohammadi, A. Hospital site selection using fuzzy AHP and its derivatives. J. Environ. Manag. 2009, 90, 3048-3056. [CrossRef]

26. Kahraman, C.; Cebeci, U.; Ulukan, Z. Multi-criteria supplier selection using fuzzy AHP. Logist. Inf. Manag. 2003, 16, 382-394. [CrossRef]

27. Khaki, A.M.; Mojaradi, B.; Ghobadipour, B.; Maghsoudy, S.; Naghibi, F. Integration of GIS and analytical hierarchy process method for locating road emergency medical services station. Geosystem Eng. 2015, 18, 92-103. [CrossRef]

28. Bahadori, M.K.; Ghardashi, F.; Izadi, A.R.; Ravangard, R. Pre-hospital emergency status in Iran with an emphasis on road accidents: A systematic review. Trauma Mon. 2015, 20, 17. [CrossRef]

29. Alluri, S.; Cattamanchi, S.; Voskanyan, A.; Sarin, R.R.; Molloy, M.S.; Ciottone, G.R. Emergency Medical Service Usage and its Effect on Outcomes in Road Traffic Accident Victims in India. Prehospital Disaster Med. 2017, 32, S164-S165. [CrossRef]

30. Balikuddembe, J.K.; Ardalan, A.; Khorasani-Zavareh, D.; Nejati, A.; Raza, O. Weaknesses and Capacities Affecting the Prehospital Emergency Care for Victims of Road Traffic Incidents in the Greater Kampala Metropolitan Area: A Cross-Sectional Study. Prehospital Disaster Med. 2019, 34, s177. [CrossRef]

31. Elvik, R. State-Of-The-Art Approaches to Road Accident Black Spot Management and Safety Analysis of Road Networks; Transportøkonomisk Institutt: Oslo, Norway, 2007.

32. Geurts, K.; Wets, G. Black Spot Analysis Methods: Literature Review; Steunpunt Verkeersveiligheid: Diepenbeek, Belgium, 2003.

33. Sørensen, M.; Elvik, R. Black Spot Management and Safety Analysis of Road Networks; Institute of transport economics: Oslo, Norway, 2007.

34. Maglogiannis, I.; Hadjiefthymiades, S. EmerLoc: Location-based services for emergency medical incidents. Int. J. Med Inform. 2007, 76, 747-759. [CrossRef]

35. McLafferty, S.L. GIS and health care. Annu. Rev. Public Health 2003, 24, 25-42. [CrossRef]

36. Ohta, K.; Kobashi, G.; Takano, S.; Kagaya, S.; Yamada, H.; Minakami, H.; Yamamura, E. Analysis of the geographical accessibility of neurosurgical emergency hospitals in Sapporo city using GIS and AHP. Int. J. Geogr. Inf. Sci. 2007, 21, 687-698. [CrossRef]

37. Schuurman, N.; Fiedler, R.S.; Grzybowski, S.C.; Grund, D. Defining rational hospital catchments for non-urban areas based on travel-time. Int. J. Health Geogr. 2006, 5, 43. [CrossRef]

38. Zhou, L.; Wu, J. GIS-Based Multi-Criteria Analysis for Hospital Site Selection in Haidian District of Beijing. Master's Thesis, University of Gävle, Gävle, Sweden, 2012.

39. Ghorbanzadeh, O.; Moslem, S.; Blaschke, T.; Duleba, S. Sustainable urban transport planning considering different stakeholder groups by an interval-AHP decision support model. Sustainability 2018, 11, 9. [CrossRef]

40. Takagi, H. Cooperative systems of neural networks and fuzzy logic and its applications. In Proceedings of the Conference Record of the Twenty-Sixth Asilomar Conference on Signals, Systems \& Computers, Pacific Grove, CA, USA, 26-28 Octomber 1992.

41. Chang, D.-Y. Applications of the extent analysis method on fuzzy AHP. Eur. J. Oper. Res. 1996, 95, 649-655. [CrossRef]

42. Saaty, T. Analytic Hierarchy Process; Wiley Online Library: Hoboken, NJ, USA, 1980.

43. Ghorbanzadeh, O.; Rostamzadeh, H.; Blaschke, T.; Gholaminia, K.; Aryal, J. A new GIS-based data mining technique using an adaptive neuro-fuzzy inference system (ANFIS) and k-fold cross-validation approach for land subsidence susceptibility mapping. Nat. Hazards 2018, 94, 497-517. [CrossRef]

44. Ghorbanzadeh, O.; Feizizadeh, B.; Blaschke, T. An interval matrix method used to optimize the decision matrix in AHP technique for land subsidence susceptibility mapping. Environ. Earth Sci. 2018, 77, 584. [CrossRef] 
45. Cabrera-Barona, P.; Ghorbanzadeh, O. Comparing Classic and Interval Analytical Hierarchy Process Methodologies for Measuring Area-Level Deprivation to Analyze Health Inequalities. Int. J. Environ. Res. Public Health 2018, 15, 140. [CrossRef]

46. Feizizadeh, B.; Roodposhti, M.S.; Jankowski, P.; Blaschke, T. A GIS-based extended fuzzy multi-criteria evaluation for landslide susceptibility mapping. Comput. Geosci. 2014, 73, 208-221. [CrossRef]

47. Lee, S.K.; Mogi, G.; Hui, K. A fuzzy analytic hierarchy process (AHP)/data envelopment analysis (DEA) hybrid model for efficiently allocating energy R\&D resources: In the case of energy technologies against high oil prices. Renew. Sustain. Energy Rev. 2013, 21, 347-355.

48. Feizizadeh, B.; Blaschke, T. An uncertainty and sensitivity analysis approach for GIS-based multicriteria landslide susceptibility mapping. Int. J. Geogr. Inf. Sci. 2014, 28, 610-638. [CrossRef]

49. Chen, S.; Saeed, T.U.; Labi, S. Impact of road-surface condition on rural highway safety: A multivariate random parameters negative binomial approach. Anal. Methods Accid. Res. 2017, 16, 75-89. [CrossRef]

50. Liao, S.-M.; Cheng, C.-H.; Chen, L.-S. The planning and construction of a large underpass crossing urban expressway in Shanghai: An exemplary solution to the traffic congestions at dead end roads. Tunn. Undergr. Space Technol. 2018, 81, 367-381. [CrossRef]

51. Nasiripur, A.; Bahadori, M.; Tofighi, S.; Gohari, M. Prehospital emergency performance in Iran View of comprehensive coverage plan. J. Crit. Care Nurs. 2010, 2, 3-4.

52. Gholipour, C.; Vahdati, S.S.; Notash, M.; Miri, S.H.; Ghafouri, R.R. Success rate of pre-hospital emergency medical service personnel in implementing pre hospital trauma life support guidelines on traffic accident victims. Turk. J. Emerg. Med. 2014, 14, 71-74. [CrossRef] [PubMed]

53. Hosseinpour, M.; Mohammadzadeh, M.; Paravar, M.; Mirzadeh, A.S. Prehospital Care and in-Hospital Mortality of Trauma Patients in Iran; Cambridge University Press: Cambridge, UK, 2015.

54. Paravar, M.; Hosseinpour, M.; Mohammadzadeh, M.; Mirzadeh, A.S. Prehospital care and in-hospital mortality of trauma patients in iran. Prehospital Disaster Med. 2014, 29, 473-477. [CrossRef] [PubMed]

55. Brooks, B.M. A Review of: "Psychology on the Road. The Human Factor in Traffic. Safety". By DAVID SHINAR. (Chichester: John Wiley \& Sons Ltd., 1978.) [Pp. xii + 212.] £9.25. Ergonomics 2007, 23, 1095-1097.

56. France-Mensah, J.; O’Brien, W.J.; Khwaja, N.; Bussell, L.C. GIS-based visualization of integrated highway maintenance and construction planning: A case study of Fort Worth, Texas. Vis. Eng. 2017, 5, 7. [CrossRef]

57. Toroyan, T. Global status report on road safety: Time for action. Inj. Prev. 2009, 15, 286. [CrossRef] [PubMed]

58. Glendon, I.A. Human Safety and Risk Management, Second Edition; CRC Press: Boca Raton, FL, USA, 2016.

59. Hoyos, C.G.; Zimolong, B. Occupational Safety and Accident Prevention: Behavioral Strategies and Methods; Elsevier: Amsterdam, Netherlands, 2014; Volume 11.

60. Reason, J. The Human Contribution: Unsafe Acts. Accid. Heroic Recover; Ashgate: Farnham Surrey, UK, 2008.

61. Goli, A.; Ansarizade, N.; Barati, O.; Kavosi, Z. Location of Road Emergency Stations in Fars Province, Using Spatial Multi-Criteria Decision Making. Bull. Emerg. Trauma 2015, 3, 8. [PubMed] 